\title{
An Ultrastructural Study of the Hyphae, Endoconidia and Chlamydospores of Thielaviopsis basicola
}

\author{
By V. G. DELVECCHIO,* R. CORBAZ AND G. TURIAN \\ Laboratoire de Microbiologie, Institut de Botanique Générale, \\ Université de Genève, Switzerland
}

(Accepted for publication I2 May 1969)

\begin{abstract}
SUMMARY
The cell wall of hyphae of Thielaviopsis basicola consisted of an inner transparent layer and an outer electron-dense layer. The cell wall of the endoconidia was usually composed of a single transparent layer; at the tip of the endoconidia distal from the phialide the cell wall protruded into the cytoplasm. Hyphal tubes that contained endoconidia were devoid of cytoplasmic components. The only cytoplasmic component recognizable in the phialide was the endoplasmic reticulum. Two complex cell-wall systems were observed in chlamydospores. An outer cell wall enclosed the whole chlamydospore and each individual compartment possessed its own separate cell wall. Both cell walls were composed of an outer very electron-dense layer and an inner layer which appeared to be electron-transparent.
\end{abstract}

\section{INTRODUCTION}

This study of Thielaviopsis basicola (Berk. and Br.) Ferraris was undertaken in an effort to determine the ultrastructure of the hyphae and two types of propagules (endoconidia and chlamydospores) produced by this fungus. $T$. basicola, which was first described by Berkeley \& Broome in 1850 , is a soil-inhabiting parasite that causes serious black root rot in the seed beds of European tobacco growers and also damages plants in the field. The conidia of $T$. basicola develop in the interior of the phialide, are successively pushed into a tube-like hypha and are eventually liberated through the apex of this hypha (Brierley, I9I5).

Chlamydospores are characterized by a thick cell wall that encloses chains of cells or compartments that contain cytoplasmic components in high densities. In Thielaviopsis basicola chlamydospores may be formed either terminally or laterally on hyphae. Patrick, Toussoun \& Thorpe (1965) demonstrated that disruption of a chlamydospore upon maturation is a prerequisite for germination of the individual compartments. Christias \& Baker (1967) reported that this disruption can be induced by the action of the enzyme chitinase.

\section{METHODS}

Organism. Thielaviopsis basicola strain 653, classified by Stover (1956) as a brown form of $T$. basicola, was chosen for study because it forms numerous chlamydospores and endoconidia in short periods of time. It is stable in cultures and is pathogenic to tobacco. Our stock was obtained from the fungus collection of the Tobacco Research 
Centre SOTA, Nyon, Switzerland. It was originally isolated in June 1967 from rootlets of Burley var. SOTA 27 grown in Corcelles, Switzerland.

Media. The organism was isolated from tobacco seedlings on the VDYA-PCNB medium of Papavizas (1964). Malt agar medium ( $2 \%$ malt extract and $2 \%$ Difco agar) was used for the maintenance of stocks and also for culture of the cellular material used for electron microscopy.

Cultural conditions. The fungus was grown in Petri dishes at $25^{\circ}$. After incubation for 4 days a dark halo formed approximately $\mathrm{I} \mathrm{cm}$. from the point of inoculation at the centre of the Petri dish. The mycelia in this area were of the type that contains endoconidia. A portion of this halo was placed in warm $\left(40^{\circ}\right) 2 \%$ agar solution which solidified immediately and thus prevented dispersion of the endoconidia.

Microscopy. Small blocks cut from the agar were kept in phosphate-buffered $2 \% \mathrm{KMnO}_{4}\left(\mathrm{O} \cdot \mathrm{I} \mathrm{M}, \mathrm{pH}_{7} \cdot 4\right)$ for $2.5 \mathrm{hr}$ at $4^{\circ}$ then washed in the buffer and allowed to stand $4 \mathrm{hr}$ in the last wash.

For electron microscopy the blocks were dehydrated in a series of acetone + water solutions, stained with uranyl acetate, and embedded in Vestopal W by the method of Kellenberger \& Ryter (1958). Ultrathin sections were cut with glass knives on a Porter-Blum ultramicrotome and mounted on Parlodion-covered grids. All observations were made with an Hitachi HS-7S electron microscope.

\section{RESULTS}

\section{Light microscopy}

Under the light microscope, unstained endoconidia could be seen within the hyphal tubes (Pl. I, fig. I). The walls of these cells appeared to be structurally distinct from the wall of the hyphal tube. Hyphal tubes from which the endoconidia had been liberated appeared as empty cylinders.

Chlamydospores, composed of several thick-walled compartments, were attached either at intercalary positions or at the tip of the hyphae that gave rise to them (Pl. I, fig. 2). Some were also observed to be lateral to hyphae. A few hyaline basal cells were visible between the hyphae and the dark spores of the chlamydospores.

\section{Electron microscopy}

Hyphae. The hyphal cytoplasm contained mitochondria, nuclei and a well developed endoplasmic reticulum (P1. I, fig. 3). These structures were similar to those described for other fungi (Moore, 1965). One differentiating feature was the ultrastructure of the hyphal cell wall which was composed of two portions: an outer electron-dense layer and an inner transparent layer.

Endoconidia and free conidia. The fine structure of endoconidia and liberated conidia was identical (Pl. I, fig. 4; Pl. 2, fig. 5, 6, 7). The cell wall of conidia lacked the electron-dense portion seen in the cell walls of hyphae. The cell walls of some conidia had a slightly electron-dense outer portion (Pl. 2, fig. 6) but the electrondensity of this portion was always considerably less than that of hyphal cell walls. In sections cut parallel to the longest axis of a conidium one centrally located nucleus could be seen flanked usually by two vacuoles and clusters of vesicles at the tips of the cell (Pl. I, fig. 4; Pl. 2, figs. 6, 7). These vesicles, which contain an unknown storage 
product, appear as blank white spaces in permanganate-fixed material. Near the vacuoles and groups of vesicles, at the tip of the endoconidium that is distal to the phialide, the cell wall protruded into the cytoplasm (Pl. I, fig. 4; Pl. 2, fig. 5, 6).

Hyphal tubes. The hyphal tubes that contained endoconidia were composed of cells which were always devoid of cytoplasmic components (Pl. 2, fig. 5, 6, 7). The walls of these cells were never attached to the walls of the endoconidia and were identical to the cell walls of vegetative hyphae.

Phialides. The phialides are large structures enclosed in the hyphal tubes (P1. 2, fig. 6). Their cell walls were essentially the same as those of the endoconidia. Their endoplasmic reticulum was clearly recognizable, but no other cytoplasmic components were visible. The cell walls of the phialides appeared to be essentially the same as those of the endoconidia. No evidence was ever found of an attachment between the wall of the phialide and the wall of a hyphal tube.

Chlamydospores. Two complex cell-wall systems were observed in chlamydospores. An outer cell wall enclosed the whole chlamydospore and thus surrounded all the compartments contained within. Each individual compartment possessed its own separate cell wall (P1. 3, fig. 8, 9, Io). The cell walls which surrounded the whole chlamydospore and the individual compartments were composed of at least two layers, an outer very electron-dense layer and an inner layer which appeared to be electron-transparent.

Plate 3 , fig. 8 shows the characteristic density of the cytoplasmic components. This particular section transversed four compartments of the chlamydospore. A nucleus is visible in one of the cells, as well as numerous mitochondria. The endoplasmic reticulum is very extensive and is composed of parallel strands that are separated by an electron-transparent lumen (Pl. 3, fig. 9).

Plate 3, fig. Io shows an electron micrograph of a 4-day-old chlamydospore with an intercompartmental pore that permits the exchange of cytoplasm between the two adjacent cells.

\section{DISCUSSION}

The exact significance of the protrusion of the cell wall into the cytoplasm at the tip of the endoconidia distal from the phialide is not definitely known. It may be a remnant of previous connection with a neighbouring conidium during formation.

The outer wall of each chlamydospore surrounds several individual compartments, each of which has its own cell wall. The function of the surrounding outer wall may be to retain the integrity of the chlamydospore until maturation and subsequent liberation of the individual compartments. Separation of compartments is necessary for germination (Patrick et al. 1965). It seems probable that the outer wall breaks down when the compartments mature. Since chitinase is able to bring about the disruption of chlamydospores (Christias \& Baker, 1967), one can theorize that the surrounding outer wall may be more susceptible to the action of this enzyme than are the walls of the individual compartments.

The pore present between the compartments of young chlamydospores allowed cytoplasmic exchange between compartments. It is quite possible that these pores do not exist in older chlamydospores. The fact that the fine structure of these pores is identical with that described by Moore \& McAlear (I962) in Ascomycetes lends support to the hypothesis that Thielaviopsis is the imperfect form of an Ascomycete. 
The content of the vacuoles and vesicles usually present at each end of the endoconidia is still unknown.

Hyphal tubes in which endoconidia were seen always lacked cytoplasmic components. This lack is similar to that seen in the host mycelia of the intramycelial mycelia of the 'clock' mutant (Lowry \& Sussman, I966) and the intraconidial conidia of 'spray' mutant (DelVecchio \& Turian, I968) of Neurospora crassa.

The phialide, observed as a rather large structure enclosed in the hyphal tube surprisingly seemed to be composed of moribund cytoplasm. However, traces of the endoplasmic reticulum were found.

This work was supported in part by Postdoctoral Research Grant 6-F2-AI-3I, 86I-02A I from the National Institutes of Health, United States Public Health Service awarded to one of the authors (V. G. D.).

\section{REFERENCES}

Berkeley, M. J. \& Broome, C. E. ( 1850 ). Notices of British fungi. Ann. Mag. nat. Hist. 30, 46I.

Brierley, W. B. (1915). The endoconidia of Thielavia basicola Zoph. Ann. Bot. 29, 483.

CHRISTIAS, C. \& BAKER, K. F. (1967). Chitinase as a factor in the germination of chlamydospores of Thielaviopsis basicola. Phytopathology 57, 1363.

DelVecchio, V. G. \& Turian, G. (I968). Intraconidial conidia in the 'Spray' mutant of Neurospora crassa. J. gen. Microbiol. 52, 888.

Kellenberger, E. \& RYTeR, A. (1958). L'inclusion a polyester pour l'ultramicrotome. J. Ultrastruct. Res. 2, 200.

LOWRY, R. J. \& SUSSMAn, A. S. (1966). Intra-hyphal hyphae in 'Clock' mutants of Neurospora. Mycologia $\mathbf{5 8 , 5 4 1 .}$

Moore, R. T. (1965). The ultrastructure of fungal cells. In The Fungi, Ed. by G. C. Ainsworth and A. S. Sussman. Vol. I, p. 95. New York: Academic Press.

Moore, R. T. \& MCAlear, J. H. (1962). Fine structure of mycota. Observations on septa of Ascomycetes and Basidiomycetes. Am. J. Bot. 49, 86.

Papavizas, G. C. (1964). New medium for the isolation of Thielaviopsis basicola on dilution plates from soil and rhizosphere. Phytopathology 54, I475.

Patrick, A. Z., Toussoun, T. A. \& ThORPE, H. J. (I965). Germination of chlamydospores of Thielaviopsis basicola. Phytopathology 55, 466.

STover, R. H. (1956). Effect of nutrition on growth and chlamydospores formation in brown and gray cultures of Thielaviopsis basicola. Can. J. Bot. 34, 459.

\section{EXPLANATION OF PLATES}

Light micrographs of Thielaviopsis basicola. Abbreviations used: $B=$ basal cells of chlamydospores; $C=$ conidiophore; $E C=$ endoconidia $; H T=$ hyphal tube which encloses endoconidia; $P=$ phialide; $C c=$ compartments of chlamydospores.

Electronmicrographs. Abbreviations used: $C I C=$ chlamydospore inner cell wall; $C O C=$ chlamydospore outer cell wall; $E R=$ endoplasmic reticulum; $H I C=$ hyphal inner cell wall portion; $H O C=$ hyphal outer cell wall portion; $M=$ mitochondria; $N=$ nucleus; $P=$ phialide; $P r=$ protuberance of cell wall into the conidial cytoplasm; $S V=$ storage vesicles; $V=$ vacuole.

\section{Plate I}

Fig. I. Endoconidia $(E C)$ enclosed in hyphal tube $(H T)$. A phialide $(P)$ can be noted at the base of the hyphal tube, and immediately beneath the phialide a conidiophore $(C) . \times 635$.

Fig. 2. Chlamydospores which contain individual compartments $(C C)$ and also basal cells $(B) . \times 250$. Fig. 3. Cell wall of a hypha composed of an electron-dense layer $(H O C)$ and an inner electrontransparent layer $(H I C) . \times 12,250$. 

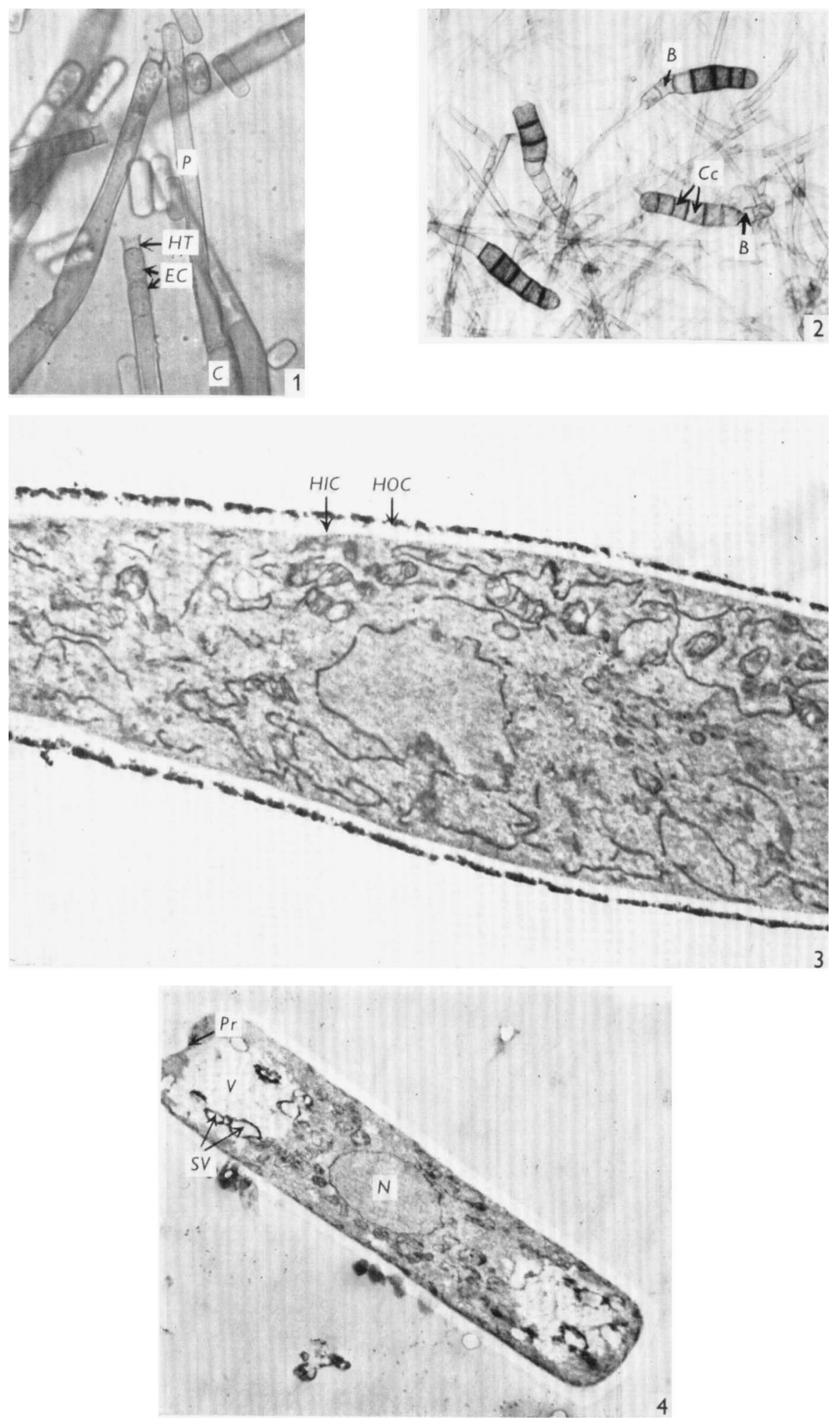

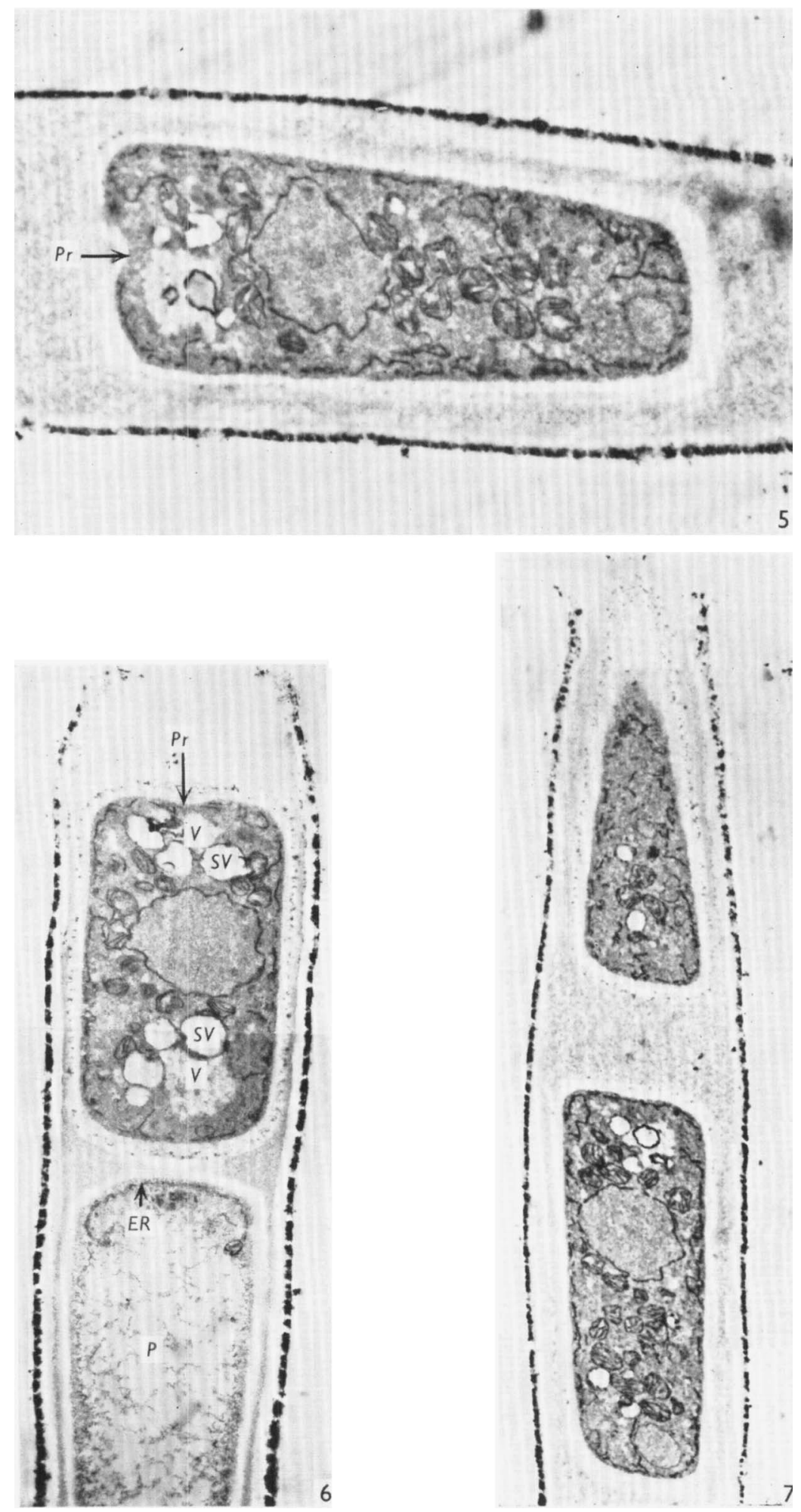

V. G. DELVECCHIO, R. CORBAZ AND G. TURIAN 

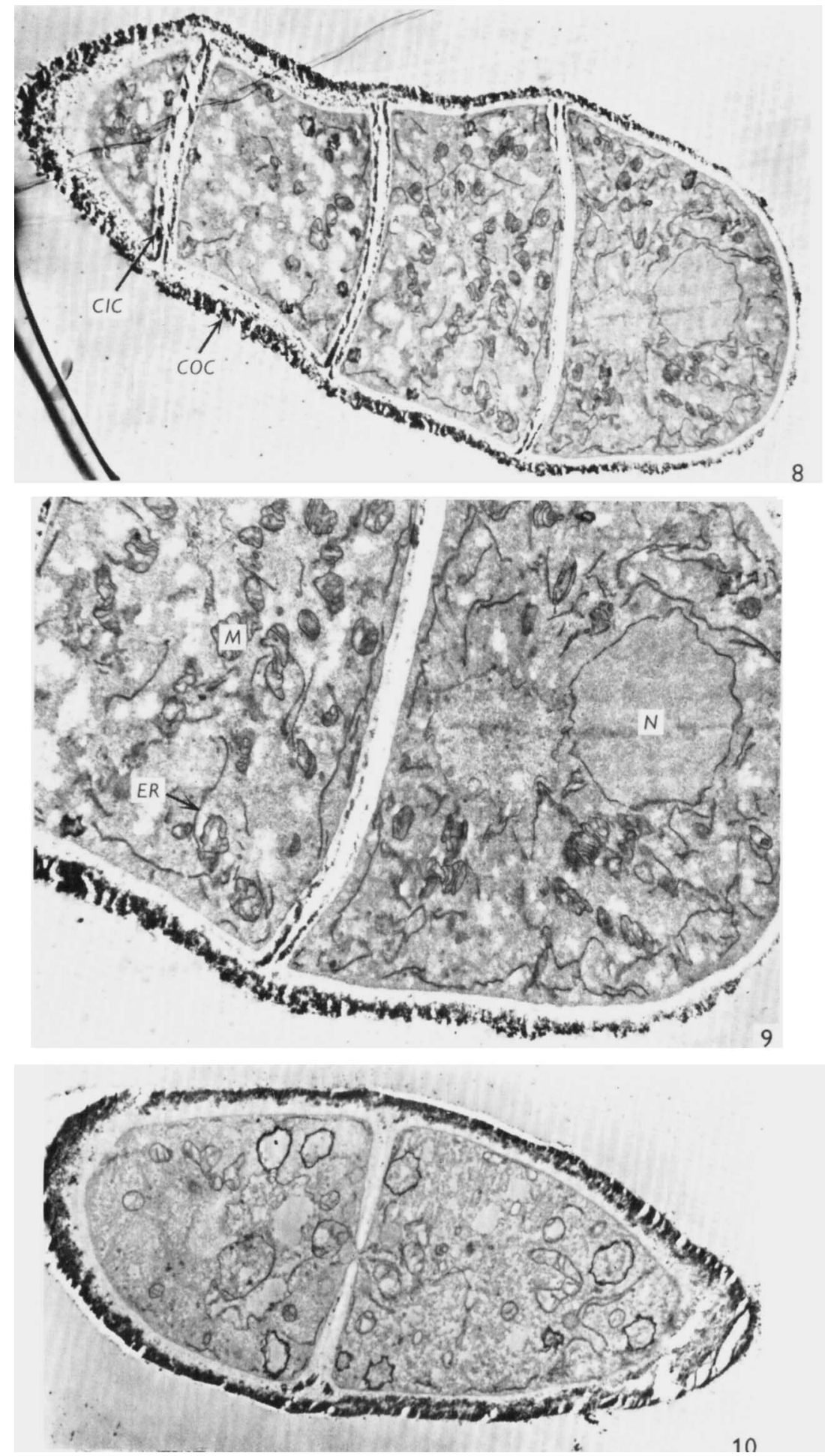

V. G. DELVECCHIO. R. CORBAZ AND ( I IIRIAN 
Fig. 4. Liberated conidium with a centrally located nucleus $(N)$ flanked by vacuoles $(V)$ and storage vesicles $(S V)$. Note the protuberance $(P r)$ of the cell wall into the cytoplasm. The wall appears as a single transparent layer. $\times 8750$.

\section{Plate 2}

Fig. 5. Section of an endoconidium contained in a hyphal tube. The protuberance (Pr) found in many conidia can be seen. The cell wall of the endoconidium is distinct from that of the hyphal tube which resembles the cell wall of normal vegetative hyphae. The hyphal tube surrounding the endoconidium lacks cytoplasmic components. $\times 14,350$.

Fig. 6. An endoconidium at the apex of its hyphal tube. A slight protuberance $(P r)$ can be seen in the conidium, as well as vacuoles $(V)$ and storage vesicles $(S V)$. Traces of endoplasmic reticulum are visible in the phialide $(P)$ that is situated just under the endoconidium. The outer portion of the cell wall of the endoconidium is slightly darkened. $\times$ I I,550.

Fig. 7. An endoconidium in process of leaving its hyphal tube. The space characteristically seen between endoconidia is clearly shown. $\times 9800$.

\section{Plate 3}

Fig. 8. Section through four compartments of a chlamydospore. Each compartment has its own cell wall $(C I C)$; the entire chlamydospore is enclosed in an outer cell wall $(C O C) . \times 6800$.

Fig. 9. The cytoplasm of a chlamydospore containing nucleus $(N)$, mitochondria $(M)$ and an extensive endoplasmic reticulum $(E R), \times 11,550$.

Fig. Io. Chlamydospore with a pore between two compartments. $\times 9540$. 